See discussions, stats, and author profiles for this publication at: https://www.researchgate.net/publication/262169576

Whole-of-government approach to information technology strategy management: Building a sustainable collaborative technology environment in government

Article in Information Polity · August 2011

DOI: 10.3233/IP-2011-0237

CITATIONS

17

3 authors:

Adegboyega Ojo

National University of Ireland, Galway

162 PUBLICATIONS 1,271 CITATIONS

SEE PROFILE

6. Elsa Estevez

Universidad Nacional del Sur

102 PUBLICATIONS 861 CITATIONS

SEE PROFILE

Some of the authors of this publication are also working on these related projects:

Project Strengthening Governance Capacity for Smart Sustainable Cities (CAP4CITY) View project

Project Electronic Voting View project
READS

344

Tomasz Janowski

144 PUBLICATIONS 1,203 CITATIONS

SEE PROFILE 


\title{
Whole-of-Government Approach to Information Technology Strategy Management: Building a Sustainable Collaborative Technology Environment in Government
}

\author{
Adegboyega Ojo1, Tomasz Janowski and Elsa Estevez \\ Center for Electronic Governance, United Nations University - \\ International Institute for Software Technology, Macao SAR, China
}

\begin{abstract}
The Whole of Government (WG) approach is increasingly seen as an imperative for delivering coherent and integrated policies, joined up and seamless services, and integrated program management in government. Although no generic WG framework currently exists, there are reported cases of WG initiatives by different governments. Grounded in existing theories, frameworks and cases related to inter-organizational collaboration, collaborative Electronic Government (EGOV) and joined-up government, this article describes how to build a collaborative IT Strategy Management (ITSM) environment based on the WG approach. The article first develops a WG model to identify the enabling elements for the WG approach. Next, it identifies the necessary conditions for creating a collaborative ITSM environment in government, applies the WG model to synthesize a set of generic requirements for implementing the WG approach, and presents a WG ITSM toolset to support the implementation. Finally, the generic WG-ITSM requirements are used to analyze a case study involving the WG-ITSM development in a city government. Based on the case study, the validity of the WG model and generic WG-ITSM requirements as well as the usefulness of the toolset are discussed. The article closes with the recommendations for the WG-ITSM practice and for further development of the WG framework.
\end{abstract}

Keywords - Whole-of-Government Framework, IT Strategy Management, Strategy Markup Language, Strategy Management Tool, StratML

\section{Introduction}

Governments are continuously seeking how to better exploit the opportunities offered by IT for raising the efficiency and effectiveness in administrative and business processes, and for improving operations. This is reflected in the increased government spending on IT worldwide, estimated at USD 428.38bn in 2009 and expected to grow by another 5\% in 2010 [45]. However, the non-abating record of failed IT initiatives is a major concern [3], giving rise to tighter regulation and coordination requirements on IT performance across government. The Government Performance and Results Act (1993) and the Clinger-Cohen Act (1996) promulgated by the US Government [47] and the comprehensive reform on the government's IT use by the Australian Government Information Management Office (AGIMO) [32] are example measures already taken by governments.

A core strategy adopted by these countries to increase the public value produced by IT is government-wide collaboration. For example, the United States Government Accountability office (GAO) expressed the need for a sustainable collaborative practice among federal agencies to effectively respond to the challenges beyond the capabilities of a single agency [46]. Similarly, the Australian Public Service Commission (APS) indicated the need for "Connecting Government" through the "Whole-of-Government" response to address the challenges faced by Australia [8]. The report describes WG as public service agencies working across portfolio boundaries to jointly achieve integrated responses to the issues of policy development, program management and service delivery. With the UK Government recognized as a pioneer in the WG approach, also Canada [19], New Zealand [42], Norway [10] and international organizations like OECD [31] have evolved their WG models.

In the IT area, the WG trend aims at improving coordination, reducing duplications and integrating IT-enabled services and policies. The trend is likely to intensify with the economic decline, greater strains on government budgets, and pressures on long-term investments. At the same time, various performance and strategy management

\footnotetext{
${ }^{1}$ Corresponding author: Center for Electronic Governance, United Nations University - International Institute for Software Technology, P.O. Box 3058, Macao SAR, email: ao@iist.unu.edu.
} 
frameworks including the Balanced Scorecard [17][28][2][33], Val IT Framework [18] and Public Value Framework [3] are available for better strategic IT management. However, successful application of the WG approach to ITSM requires the knowledge of the WG-ITSM requirements for specific application contexts and the presence of WG-ITSM frameworks to address such requirements. Unfortunately, methods to determine the former and examples of the latter are scarce. Apart from the AGIMO [32] and GAO [47] initiatives, little is known about the WG approach to IT investment in government. While a number of publications exist on concrete WG applications [8][19][42][10], the literature on WG initiatives aimed at strategic use of IT are limited.

However, studies exist on improving inter-agency collaboration related to IT. For instance, [38] describes collaboration between agencies which jointly deliver government services, and highlights the underlying issues of data ownership, institutional frameworks and dynamic nature of collaborative relationships. In another study, organizational aspects of such collaboration were investigated using a system dynamics model for socio-technical processes emerging from the interactions between partner organizations [26]. On the social aspect, [27] examines how trust, knowledge of partners and facilitation skills in cross-agency use of IT affect collaboration.

This article contributes to the emerging understanding of the WG approach in general and WG-ITSM in particular. It explains what is involved in developing a WG approach and what this approach signifies in the ITSM context in government. Specifically, the article develops a WG model that identifies the core elements for implementing the WG approach. Using the model, it synthesizes a set of generic requirements (WG-ITSM framework) to guide the implementation of the WG-ITSM environment. To support the implementation, a WG-ITSM toolset is proposed comprising: 1) a model representing government IT strategies, their relationships and constraints; 2) the IT strategy process through which agencies can develop their IT strategies; and 3) a technique for WG integration of IT strategies. The framework also provides some tools: 4) templates to support the execution of the strategy process; 5) a pair of strategy markup languages - StratML and smXML to standardize the representation and integration of strategies; and 6) a software system for documenting, integrating and aligning agency IT strategies. Finally, the generic WG-ITSM requirements are used to analyze a case study involving the development of a WG-ITSM environment in a city government, helping to validate the WG model, the WG-ITSM generic requirements and the WG-ITSM toolset. The article concludes with the recommendations for building a sustainable WG-ITSM environment and recommends how the emerging WG framework can be further developed.

The rest of this article is organized as follows. Section 2 provides the methodology adopted to guide this research, followed by a conceptual framework for collaborative government ITSM in Section 3. Section 4 presents a WG model which is applied to develop a WG-ITSM framework in Section 5. A real-life case study in the usage of the framework is presented in Section 6, followed by validation arguments in Section 7. Discussion is presented in Section 8 and recommendations and future work in Section 9.

\section{Research Methodology}

The methodology adopted to guide this research involves the following steps:

1. Conceptualizing ITSM - The work has been grounded in public sector ITSM and collaborative EGOV. The former identifies the core elements of government ITSM and concrete frameworks employed in practice. The latter examines existing literature on collaboration and EGOV. The outcome is documented in Section 3.

2. Developing WG Model - Relying on the outcome of Step 1 and the emerging WG literature, this step develops a model to identify the core elements for implementing the WG approach, including the factors for obtaining concrete benefits from it. The outcome is documented in Section 4.

3. Operationalizing WG-ITSM - Relying on the outcome of Step 2, this step defines WG-ITSM and operationalizes this definition into a set of generic requirements. The outcome is documented in Section 5.

4. Case Study - Relying on the outcome of Step 3, this step applies the generic WG-ITSM requirements as an interpretive framework to identify concrete WG-ITSM requirements for a case study. The case study relies on the data from two surveys. The outcome is documented in Section 6.

5. Validation - The final step is to validate the WG model and generic WG-ITSM requirements, and demonstrate the coverage of the WG-ITSM toolset based on the case study. The outcome is documented in Section 7. 


\section{Collaborative IT Strategy Management in Government}

The conceptual framework underpinning this work links two research lines: IT Strategy Management (ITSM) and collaboration in government. This section introduces the framework in three steps: conceptualizing ITSM, conceptualizing collaboration in government, and linking ITSM with collaboration in government.

\subsection{Conceptualizing IT Strategy Management}

There are a number of schools of thought regarding the meaning of Strategy and the nature of the Strategy Process. [1] defines Strategy as a coherent and integrative pattern of decisions that determines and reveals the purpose of an organization in terms of its long-term objectives, action programs and resource allocation priorities. [16] defines a Strategy Process as both a formalized procedure and a learning process comprising strategy formation and planning.

Based on the developed strategies, in order for an organization to build the required capabilities and create value for its stakeholders, it must engage in Strategy Management [34]. One of the most influential Strategy Management methods is Balanced Scorecard (BSC) [35]. BSC enables organizations to translate their strategies into actions, measuring organizational performance using financial as well as customer, business process, and learning and growth perspectives. The public sector adaptation of BSC focuses on [28][33]: agency mission, stakeholder interests, public value, and benefit and cost optimization. It also considers financial as well as social costs [33]. Within an organization, a unit-level BSC can be linked to the organization-level BSC through cascading [33].

ITSM is an integral part of the strategic management system of any organization. It involves: 1) development of IT strategies to meet performance targets, 2) development of IT-related capabilities to enable IT strategy implementation and 3) IT performance management to monitor and control the implementation. Typically, the government's IT management function is concerned with making sure that IT [47]:

○ delivers value to citizens, businesses and the public at large;

- supports business and administrative processes towards operational excellence;

o enables collaboration in government and compliance with government regulations; and

○ supports organizational growth and the acquisition of IT skills and competences.

These concerns are usually managed through the agency ITSM system which could be implemented using a BSC specialized for an IT organization (IT-BSC). Typically, IT performance measurement is carried out at various levels and in different areas, for instance [47]: strategic enterprise, customer, internal operations, and learning and innovation. Other government value frameworks applicable to ITSM include: US Value Measuring Methodology (US-VMM), Australian Demand and Value Assessment Methodology (D\&VAM), the e-Government Economics Project, CTG Public Value Framework, Gartner's Government Performance Framework, and the Federal Enterprise Architecture Performance Reference Model (FEA) [3][37]. The perspectives covered by these frameworks are shown in Table 1. Other IT-BSC perspectives include references to standards like ISO9001, EFQM or TQM [12].

Table 1: Perspectives Covered by Government Value Frameworks

\begin{tabular}{l|l|l|l}
\hline US-VMM & D\&VAM & CTG & Garner \\
\hline $\begin{array}{l}\text { customer value } \\
\text { social value } \\
\text { operational value } \\
\begin{array}{l}\text { financial value } \\
\text { strategic value }\end{array}\end{array}$ & $\begin{array}{l}\text { agency benefits and value } \\
\text { strategic value } \\
\text { consumer financial benefit } \\
\text { social benefit } \\
\text { governance value }\end{array}$ & $\begin{array}{l}\text { financial value } \\
\text { political and social value } \\
\text { strategic value } \\
\text { ideological value } \\
\text { stewardship value }\end{array}$ & $\begin{array}{l}\text { constituent services } \\
\text { political and strategic return } \\
\text { operational efficiency }\end{array}$ \\
\end{tabular}

In supporting a multi-perspective IT performance system such as IT-BSC, the associated IT strategy process should support organizational strategy, and assure consistency between strategies arising from different perspectives (strategic alignment) [6]. In addition, developing the necessary capabilities and resources for implementing IT strategies requires the alignment of the IT strategy process with the organizational budgeting system [6].

A conceptual model for ITSM is presented in Figure 1. 


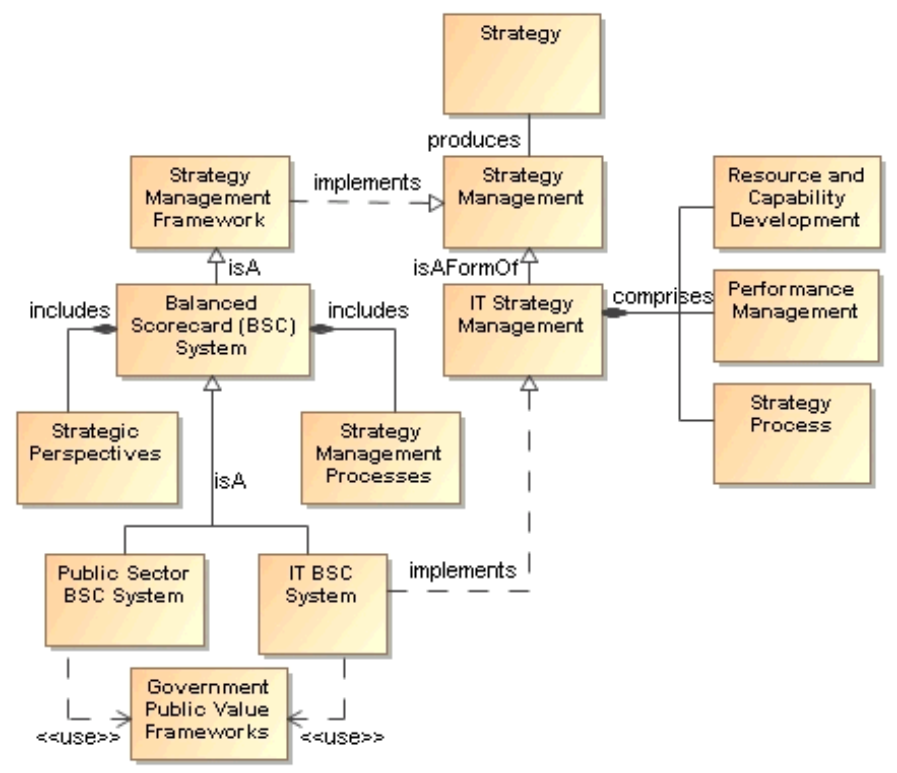

Figure 1: Conceptual Model for ITSM

\subsection{Conceptualizing Collaboration in Government}

The WG approach relies on collaboration in government, a joint activity intended to produce public value beyond the capacity of any single agency [46]. As a process, collaboration involves sharing norms and engaging in mutually beneficial interactions, occurring over time as the actors interact through negotiation, and the development and execution of commitments [4]. The elements of a collaboration process are [4]: 1) governance - actors jointly agree on the rules to guide their relationships, to share powers, and to reach agreements on the goals and how to reach them; 2) administration - clarifying the roles of actors and putting in place the coordination and monitoring machinery; 3) organizational autonomy - reconciling collective and actor-specific interests; 4) mutuality - how the actors can accrue mutual benefits; and 5) social norms - building trust and encouraging reciprocity.

A network-centric perspective conceptualizes collaboration as a self-organizing relationship among actors, able to communicate and elicit action, and with two capabilities essential for collaboration - ability to organize working relationships and ability to transmit information [13]. ARCON [25], a network-centric model of collaboration, specifies four collaboration stages: 1) creation - initiating collaboration; 2) operation - commencing actions and exchanges; 3) evolution - making required changes, and 4) dissolution -transformation and termination. The model complements the horizontal collaboration elements [4]. Figure 2 shows how these models could be integrated.

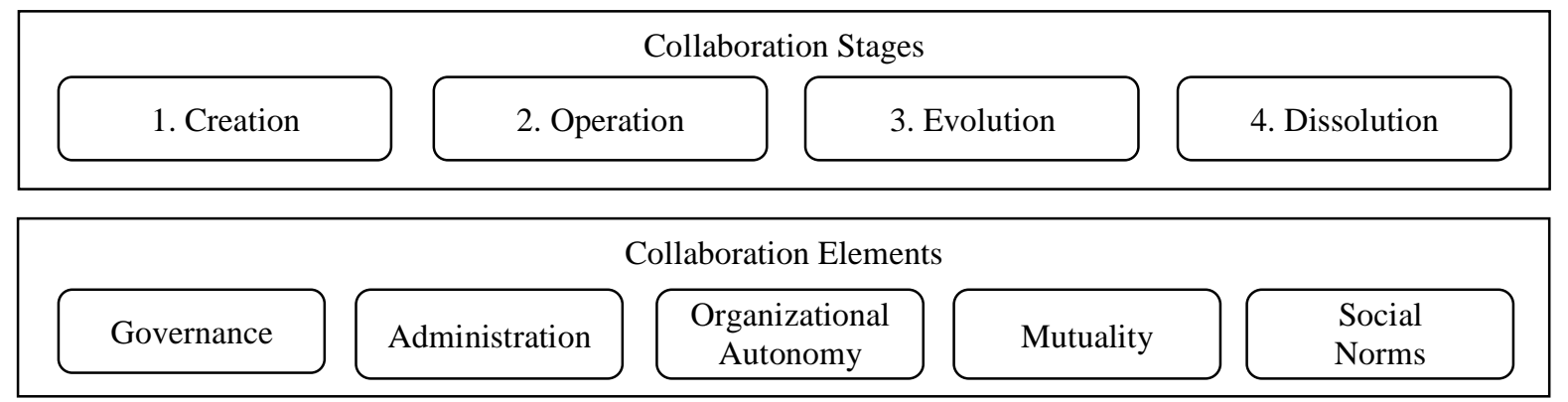

Shared Collaboration Goals

Figure 2: Collaboration Stages, Elements and Goals 
Collaboration in government is usually driven by the need to address the challenges that are beyond the capability of any single agency or level of government, e.g. in the areas of national security, public health management or natural disasters [44]. Specific goals include: 1) policy formation through interactions between actors with different interests; 2) overcoming asymmetries in agencies; 3) using non-government entities to deliver public services and fulfill policy goals; and 4) providing integrated services by different levels of government [14].

The actors involved in inter-agency collaboration could play providing, contributing, reputation-building or constitution-building roles [13]. Providers deliver the required services or policy advice. Contributors create an enabling environment for providers. Reputation-builders maintain trustworthiness status of providers. Constitutionbuilders support the planning, political advocacy and internal negotiation among providers.

Inter-agency collaboration faces a number of technical, organizational and political barriers such as the lack of agreement on goals, lack of funding, external influences over decision making, and organizational self interest [39][22]. Another barrier is the lack of alignment between motivations of participating organizations [20].

\subsection{IT Strategy Management and Collaboration in Government}

IT-related collaboration between agencies can occur at different levels: strategic - agencies collaborate to jointly deliver IT-enabled public services and develop integrated policies; organizational - agencies work together to create the enabling IT environment to carry out strategic initiatives; and solution - agencies share services, applications and infrastructure to reduce acquisition and operating costs. The goals of collaborative ITSM in government include:

- eliminating the duplication of IT investments across agencies;

- ensuring the coherence of IT strategies across agencies;

○ ensuring that agencies can develop IT capabilities by utilizing the capabilities in other agencies; and

$\circ$ integrating policy recommendations and services across different sectors and levels of government using IT.

A coordination machinery is required for collaborative ITSM in order to [32]: ensure a consistent application of IT policies, guidelines and best practices through an effective compliance regime; and coordinate and monitor IT strategy development, investment and implementation across agencies.

\section{Whole-of-Government Model}

This section presents a WG model based on the conceptualization in Section 3. It identifies major elements of the model and core principles underpinning the realization of these elements.

The WG approach involves a set of processes aimed at making agencies work together across portfolio boundaries to achieve shared goals and integrated responses to the issues of policy development, service delivery, program management, etc. [8][36]. In the program management area, WG aims at achieving greater harmonization among actors, and across analysis, planning, implementation, management and evaluation activities [10]. While many collaborative activities may not be complex, WG is usually associated with significant challenges like public health management, homeland security, natural disaster response, etc. The benefits of the WG approach are [5]: delivery of holistic responses to policy issues, particularly the problems that transcend agency boundaries; providing administrative solutions to the problem of departmentalism; providing incentives for departments to look beyond their narrow interests; enabling seamless services; and reducing duplication across departments.

A WG initiative, like any collaborative activity requires: shared objectives, leadership and governance structures, coordination mechanisms, budgeting and resource prioritization processes, methods for strengthening the social norms, accountability measures, negotiation mechanisms, mechanisms for flexible delivery and IT infrastructure [42][19]. However, WG initiatives must also balance agency-specific and WG interests, and consider regulatory, public administration and other reform programs [36]. In this regard, WG good practices include [46][44]: clear shared outcomes, mutually reinforcing strategies, agreements on agency roles and responsibilities, compatible policies and procedures across agencies, monitoring the learning and sharing of good practices, reinforcing the accountability of agencies for collaborative efforts, and the use of sanctions or disincentives for non-compliance. 
As the WG approach is deeply transformational, it requires dynamic capabilities for transitioning from one stage to another [9]. The stages are [9]: stovepipes, integrated organizations, nationwide portals, inter-organizational integration, and demand-driven joined-up government; while the capabilities are: integration, collaboration agreement, leadership, education and governance. In addition, flexibility of service delivery must be highlighted [9] and associated with the transformational perspective of WG [24].

Leadership is a major determining factor for successful WG initiatives, implicitly expressed through collaboration structure, processes and participants [11]. However, like other collaborations, implementing the WG initiatives has to overcome the differences in organizational cultures, structures and priorities [5].

From the practical perspective, building on the conceptual framework in Section 3, Table 2 summarizes the principles to guide the implementation of the WG initiatives and specific concerns associated with the governance, administration and organization, and delivery elements. Governance, administration and organization concerns are provided in [4], delivery concerns in [9][24] and guiding principles in [4] [46] [44]. For all concerns, concrete mechanisms should be developed to implement and track the principles. For example, governance mechanisms to build and maintain trust during a WG initiative are essential for sustainability. In addition, the three categories of concerns are critical in creating, operating and evolving WG initiatives (Figure 2) albeit to varying degree.

Table 2: WG Elements, Principles and Concerns

\begin{tabular}{|c|c|c|c|}
\hline & \multicolumn{3}{|c|}{ Elements } \\
\hline & Governance & Administration and Organization & Delivery \\
\hline 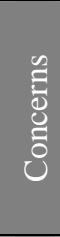 & $\begin{array}{l}\text { Establishing relationships } \\
\text { Determining membership } \\
\text { Sharing decision power } \\
\text { Creating agreements } \\
\text { Ensuring agreements compliance } \\
\text { Establishing rules to guide behavior }\end{array}$ & $\begin{array}{l}\text { Defining roles and responsibilities } \\
\text { Defining accountability procedures } \\
\text { Assuring coordination } \\
\text { Providing interoperation guidelines } \\
\text { Monitoring individual and shared goals }\end{array}$ & $\begin{array}{l}\text { Supporting flexibility } \\
\text { Supporting integration }\end{array}$ \\
\hline$\frac{\infty}{\frac{0}{2}}$ & \multicolumn{3}{|c|}{$\begin{array}{ll}\text { Trust } & \text { Sharing with peers } \\
\text { Shared objectives } & \text { Peer learning } \\
\text { Balancing shared and individual objectives } & \text { Reciprocity } \\
\text { Mutual reinforcement } & \end{array}$} \\
\hline
\end{tabular}

From the theoretical perspective, the determining factors for the WG approach are [39][22][11][9][29][4]: structure, coordination, leadership and process (governance, integration, administration or delivery). However, the perception of collaboration barriers could moderate the realization of anticipated benefits from the WG initiatives. Leadership is a particularly important determinant [11]. Figure 3 provides a possible theoretical model for the WG approach, identifying the determining and moderating factors and the relationships between them; we assume that "enable", "build" and "contextualize", but not "moderate", name the determining relations. As a first step towards validating the model, Table 3 refers to the literature sources of the relationships. Empirical analysis of such factors based on concrete cases, such as our case study in Section 6, will allow for further refinement of this model.

Table 3: WG Determining Relationships - Literature Sources

\begin{tabular}{l|l|l}
\hline No & Relationships & Sources \\
\hline 1 & Structure is an object of Coordination & {$[29]$} \\
\hline 2 & Structure contextualizes Leadership & {$[11]$} \\
\hline 3 & Process contextualizes Leadership & {$[11]$} \\
\hline 4 & Coordination enables Capability & {$[4]$} \\
\hline 5 & Leadership enables Capability & {$[9]$} \\
\hline 6 & Processes builds and enables Capability & {$[9][29]$} \\
\hline 7 & Experience moderates Benefit & {$[22]$} \\
\hline 8 & Barrier moderates Benefit & {$[39][22]$} \\
\hline
\end{tabular}




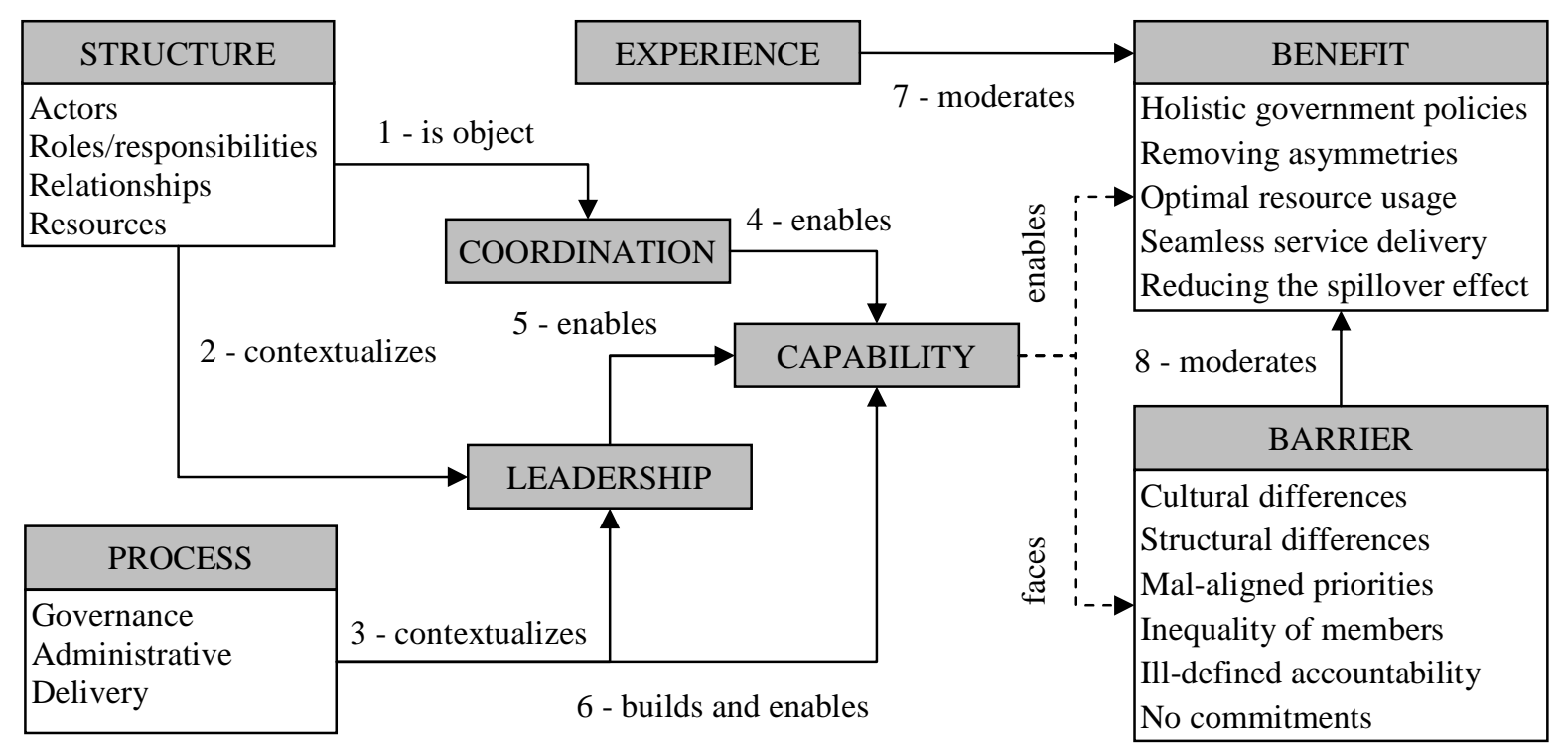

Figure 3: Emerging Conceptual Model for the WG Approach

\section{Whole-of-Government IT Framework}

In this section, we apply the WG model from Section 4 to identify generic requirements for adopting the WG approach to ITSM and also present a set of models and tools to support the implementation of the framework.

\subsection{WG-ITSM Framework}

We apply the core elements, their associated concerns and the underlying principles identified in the WG model to drive the synthesis of a generic set of requirements for WG-ITSM. Before identifying these requirements, we begin by presenting our understanding of the WG-ITSM concept.

In Section 3.1, we conceptualized ITSM to include three activities: developing the IT Strategy, developing ITrelated capabilities, and monitoring and evaluation of the strategy implementation. When we combine ITSM with the WG concept, there are two possible interpretations:

1. Applying WG principles and processes to improve the ITSM practice in government, or

2. Developing the ITSM practice that inherently supports WG initiatives in government.

The first involves the development of a virtual IT organization across the government, with no specific application goal. Adopting this definition makes any developed WG IT capability latent until applied. Adopting the second definition requires the support from a virtual IT organization indicated in the first definition. Therefore we consider WG-ITSM to include both the creation of a virtual IT organization in government and the strategic application of this organization in furthering WG initiatives. This is consistent with ICT having an impact at different levels (primary, secondary or tertiary) when viewed in a larger context (ensemble) and directed at specific activities [30]. Thus we consider WG-ITSM as a strategic enabler for any WG initiative, part of a larger WG context. From the strategic alignment perspective [35], WG-ITSM should provide strategic support and enable WG innovation.

Guided by this definition, the WG model in Figure 3, and the concerns in Table 2, we identify a set of WG-ITSM requirements to enable the implementation of the WG approach to ITSM. These requirements aim at building the governance, administrative and organizational support, and delivery mechanism required for developing and sustaining the WG-ITSM practice. The model in Figure 4 shows these elements of the WG-ITSM framework. 


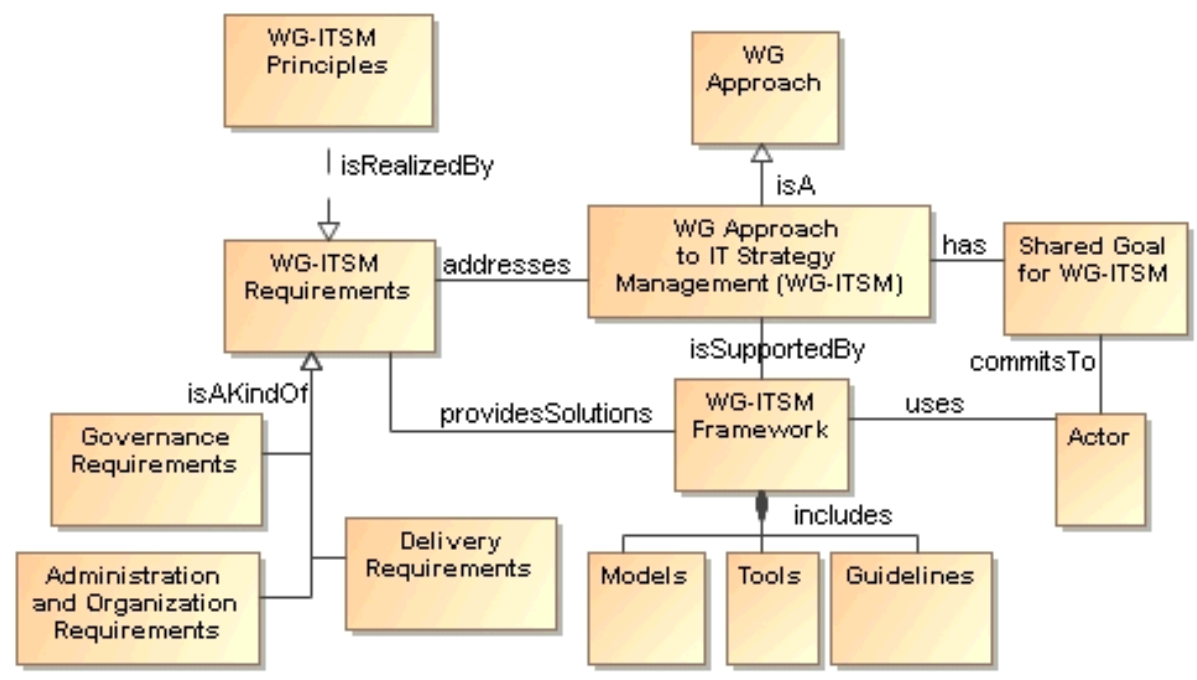

Figure 4: WG-ISTM Conceptual Model

Table 4 below provides the resulting list of WG-ITSM requirements, together with the WG elements responsible for implementing them. While the table omits the governance, administrative, organization and delivery requirements which are not specific to ITSM, all concerns identified in Table 2 would have to be considered in practice.

Table 4: Generic WG-ITSM Requirements

\begin{tabular}{l|l|l}
\hline Id & Requirement & WG Element \\
\hline GR1 & Developing and communicating shared ITSM objectives & Leadership \\
\hline GR2 & $\begin{array}{l}\text { Providing a platform to share agency-specific ITSM objectives, and IT-related } \\
\text { capabilities and good practices among agencies }\end{array}$ & $\begin{array}{l}\text { Structure } \\
\text { Coordination }\end{array}$ \\
\hline GR3 & $\begin{array}{l}\text { Facilitating social interactions among agencies through communities of practice } \\
\text { and similar structures to discuss, debate, resolve and agree on issues }\end{array}$ & Process (Social) \\
\hline GR4 & $\begin{array}{l}\text { Supporting agencies in developing IT strategies and management systems, in } \\
\text { line with their missions and aligned with WG-ITSM objectives }\end{array}$ & $\begin{array}{l}\text { Process } \\
\text { (Administrative) }\end{array}$ \\
\hline GR5 & $\begin{array}{l}\text { Coordinating IT strategies across agencies to facilitate mutual strategic support } \\
\text { and reinforcement, while preventing negative effects of strategy interactions }\end{array}$ & Coordination \\
\hline GR6 & $\begin{array}{l}\text { Determining which agencies should be included in collaboration and which, } \\
\text { given their strategic IT direction and capabilities, could be involved }\end{array}$ & Process (Governance) \\
\hline GR7 & Providing platforms to monitor compliance and alignment & Process (Governance) \\
\hline GR8 & $\begin{array}{l}\text { Providing platforms to support agencies in developing IT strategies in an } \\
\text { integrative way, including access to the IT strategies produced by other agencies }\end{array}$ & Process (Integration) \\
\hline GR9 & Making sure that IT strategy-related information is interoperable & Process (Integration) \\
\hline
\end{tabular}

There are few frameworks to support the realization of these requirements. Among them is the use of technical standards to make IT strategies and the ITSM practice in an agency compatible. Such standards can be coordinative - protocols or interfaces promoting interoperability of systems used by interacting organizations, or regulative limiting the operations of the agencies involved [43]. WG-ITSM could adopt any combination of these approaches. For instance, the US Federal Government relies on regulatory instruments such as the GPRA (1993) or the ClingerCohen (1996) acts in its WG framework, while the EU countries tend to use coordination-oriented standards. 
In the technical aspect, an initiative aimed at the Extensible Markup Language (XML) -based standardization of strategy development and performance management in government, is the Strategy Markup Language (StratML). StratML aims at standardizing the expression of strategic goals [41], enabling collection and reporting of strategies and efficient discovery of strategic plans and sharable services, and supporting strategic alignment on networks [41]. From the governance perspective, StratML enables compliance with the e-Government Act in the US, requiring agencies to link performance goals and adopt open standards to enable interoperability of strategic plans [40].

\subsection{WG-ITSM Toolset}

As depicted in Figure 4, the WG-ITSM Toolset supports the implementation of the generic WG-ITSM requirements listed in Table 4. The toolset consists of a collection of seven models, guidelines and tools: Strategy Management Model (MM), Strategy Process Model (PM), Strategy Integration Model (IM), Strategy Guidelines (SG), Strategy Templates (ST), Strategy Markup Language (smXML) and Strategy Management System (SMS). The details of these models, guidelines and tools are presented below.

Strategy Management Model (MM) - The model defines, relates and constrains the elements of an IT strategy and IT performance scorecard, and provides an object model for the design of the smXML representation of strategic plans. The model organizes IT strategies around higher-level IT goals stemming from the vision statement and associated with IT perspectives. Shown in Figure 5, the model includes linkages between IT strategies associated with different perspectives to achieve alignment; strategies could support or require support from other strategies.

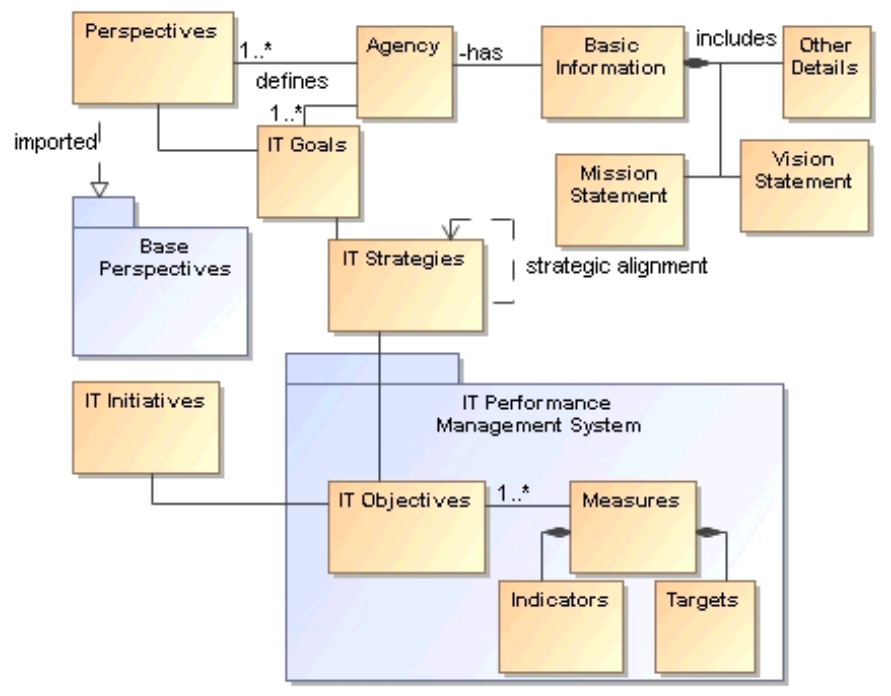

Figure 5: Strategy Management Model

Strategy Process Model (PM) - Based on several strategy process models [6], PM follows the design school [1][16] and includes seven generic steps as follows [6]:

1. Planning - Obtaining approvals and commitments, identifying stakeholders, constituting strategy and project teams, developing schedules and mobilizing resources;

2. IT Strategic Framework - Reviewing organizational and IT missions, designing IT vision and setting IT goals;

3. IT Capability Assessment - Assessing the IT environment from technical, organizational and managerial perspectives, and providing baseline information for the IT planning process;

4. Strategy Development - Developing strategies based on IT capability assessment and the analysis of strengths, weaknesses, opportunities and threats of an organization. In addition, refining IT strategies into IT objectives, measures and targets, and mapping these objectives to understand the cause and effect relationships.

5. Strategy Implementation - Deriving and prioritizing concrete IT initiatives from the IT objectives.

6. Strategy Control - Supporting continuous alignment of IT strategies with changes in the environment.

7. Strategy Documentation - Drafting the IT strategy, and obtaining feedback from stakeholders. 
Strategy Integration Model (IM) - The model, depicted in Figure 6, prescribes how IT strategies of different agencies can be related through upper-level perspectives which, once agreed, can be specialized by an agency.

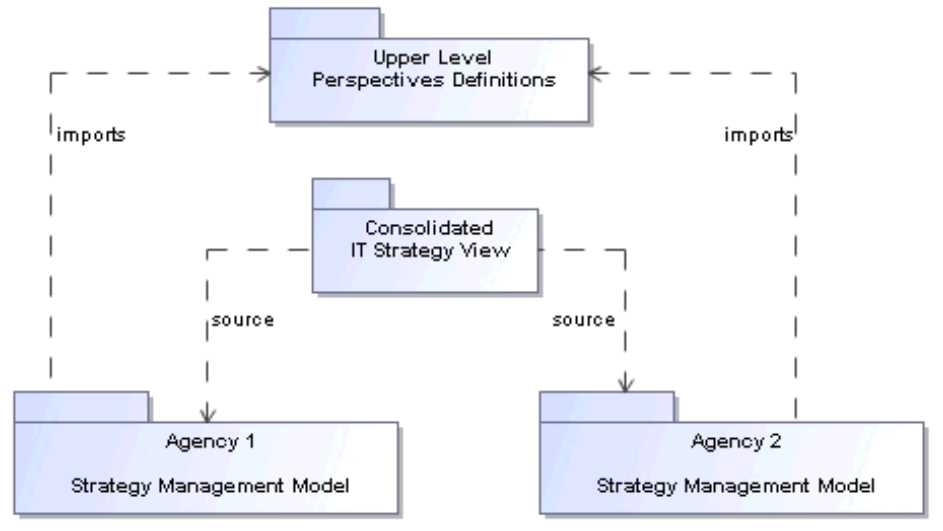

Figure 6: Strategy Integration Approach

Strategy Guidelines (SG) - Documented in [6], the guidelines are designed to assist agencies in developing IT strategy processes, based on PM and supporting the IT strategy practice satisfying control objectives of the COBIT (Control Objectives for Information and Related Technology) and IT Balanced Scorecard (BSC-IT) methods. In particular, the guidelines explain process instantiation and explain how to carry out process steps.

Strategy Templates (ST) - Documented in [7], the templates support various steps of the IT strategy process for a typical agency: stakeholder analysis, IT capability assessment, IT visioning and goal setting, IT strategy development, IT objectives development and strategic mapping of IT objectives.

Strategy Markup Language (smXML) - smXML [23] is an XML vocabulary for representing strategic IT plans and IT performance scorecards based on MM. An smXML strategic IT plan representation includes for each agency its: name; mission; vision; perspectives; goals; strategies with dependency relations; objectives with performance measures, indicators and targets; and projects implementing the objectives. Figure 7 depicts a fragment of the XML schema that defines the structure of smXML documents.

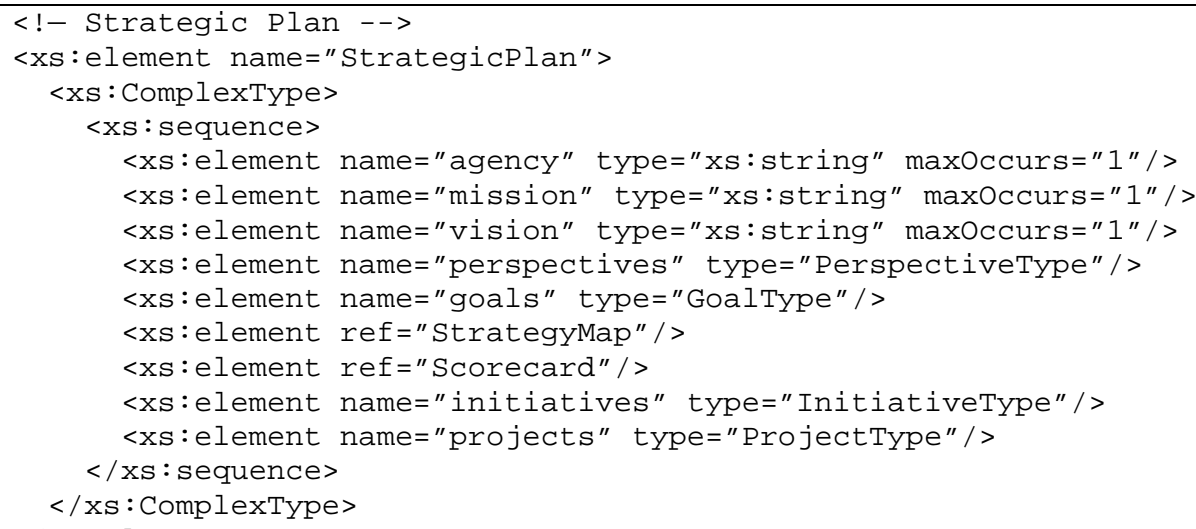

Figure 7: Schema for smXML - IT Strategy Plan Representation

Strategy Management System (SMS) - Strategy Management System (SMS) is a tool that enables the development, analysis and reporting of IT strategies and scorecards, as well as centralized management, integration and alignment of IT strategies. SMS supports: generating formatted IT strategies, exporting IT strategies to smXML for integration, analyzing alignment between agency-level and government-wide IT strategies, analyzing alignment between government-wide IT programs, and reporting in pdf, smXML and StratML formats [23]. 


\section{Case Study}

This section presents the application of the WG Model, generic WG-ITSM requirements and the WG-ITSM toolset in a real-life case study. The case study was carried out as part of administrative reform in a city government, involving a study of the technology environment in selected agencies as a basis for recommending appropriate management and technical standards to facilitate a coordinated WG-ITSM practice. This section discusses the design of the study, the findings and their analysis.

\subsection{Study Design}

We outline the goals, sources and nature of collected data, and the analysis carried out on this data:

- Goals - The study aimed at producing policy recommendations in two areas: 1) leadership and guidance for coordinating the ITSM practice and 2) developing the capacity in difference agencies for the ITSM practice in support their missions and government-wide EGOV goals.

- Data Gathering - The data used in the case study was obtained from two surveys. The first survey involved 44 agencies (about 80\%), providing information on the perceptions of agencies on EGOV, and helping strengthen the reliability of findings from the second survey through triangulation. The second survey involved 10 agencies, providing data on the state of practice in strategic management and ITSM, and perceptions on WG and cross-agency ITSM. Collected data was augmented with information gathered from the interviews with agency personnel. Questionnaires were used as primarily instruments in both surveys.

- Analysis - The data from the first survey was quantitatively analyzed to determine agency perceptions on EGOV as a WG initiative and priority factors for implementation. Guided by WG-ITSM generic requirements, the data from the second survey was qualitatively analyzed to produce specific WG-ITSM requirements.

\subsection{Findings}

The following summarizes the findings from the surveys and interview sessions in selected agencies:

F1. Perception on EGOV as WG initiative - Over $90 \%$ of the agencies participating in the first survey perceived the EGOV program as a WG initiative.

F2. Top priorities in realizing EGOV as WG initiative - Among the agencies participating in the first survey, $61 \%$ considered direction and leadership as top priorities for EGOV, while $35 \%$ considered the availability of legislation and $23 \%$ the inter-agency coordination as one of top two priorities.

F3. Direction of EGOV - Based on the second survey, only 3 responding agencies knew the general direction of the EGOV program and among them, only 2 were aware of a concrete government-wide strategy.

F4. Barriers to implementing the WG approach - From the second survey, the agencies identified several threats to successful implementation of cross-agency and WG initiatives (including EGOV): organizational changes; conflicts in implementation timing; inadequate resources; readiness and resistance of internal stakeholders; security; incompatible technological platforms; different organizational cultures; different priorities, goals and visions among agencies; different levels of expectation; legislation; weak coordination; and difficulties in negotiating and compromising.

F5. Agency experiences in cross-agency initiatives - According to the second survey, $75 \%$ of the respondent agencies confirmed prior experience in cross-agency initiatives.

F6. Issues revealed - The issues listed in Table 5 were obtained from the analysis of the completed questionnaires used for the second survey with respect to organizational and cross-agency ITSM practices.

Table 5: WG-ITSM-related Issues Revealed by the Study

\begin{tabular}{l|l|l}
\hline Id & Issue & WG Element \\
\hline I1 & Lack of understanding of the overall EGOV direction and plan & Leadership \\
\hline I2 & Weak support for the agencies to develop EGOV plans & Process (Governance) \\
\hline
\end{tabular}




\begin{tabular}{l|l|l} 
I3 & Weak alignment between agency-specific and government-wide EGOV programs & Process (Integration) \\
\hline I4 & Lack of knowledge of the agencies' EGOV programs by their staff & Leadership \\
\hline I5 & Concerns with implementation of government-wide programs & Barrier \\
\hline I6 & Lack of strategic planning framework & Process (Governance) \\
\hline I7 & Limited capacity in strategic planning & Structure \\
\hline I8 & Lack of IT standards & Coordination \\
\hline I9 & Most initiatives are implementations of a few project types & Structure \\
\hline I10 & Weak linkage between major EGOV programs & $\begin{array}{l}\text { Coordination } \\
\text { Process (Integration) }\end{array}$ \\
\hline
\end{tabular}

\subsection{Analysis of Findings}

We analyze the findings from Section 6.2 to identify the core factors enabling WG initiatives, the barriers to such initiatives, and concrete WG-ITSM recommendations (requirements) to overcome them.

The findings show that leadership, availability of legislative instruments and coordination are the core factors for developing WG initiatives (F1 and F2). The lack of agencies' knowledge of the EGOV direction (F3) is consistent with the perceived need for leadership in driving WG initiatives. Given that the agencies in the second survey had prior WG experience (F5), the barriers (F4) are not just perceptions but based on experience.

In terms of the identified WG-ITSM-related issues (F6), plausible causes based on the findings, interview sessions and first-hand knowledge of the study and its environment were analyzed and documented by the project team. They informed concrete recommendations to address the issues in Table 5, presented as requirement in Table 6, including the associated issues and WG-ITSM generic requirements.

Table 6: Specific WG-ITSM Requirements

\begin{tabular}{l|l|l|l}
\hline Id & Specific Requirement & $\begin{array}{l}\text { Related } \\
\text { Issues }\end{array}$ & $\begin{array}{l}\text { Generic } \\
\text { Requirements }\end{array}$ \\
\hline SR1 & Establishing a way to cascade strategies down organizational hierarchies & I1 & GR1, GR4 \\
\hline SR2 & Providing guidelines to agencies on how to develop IT strategies & I2 & GR4 \\
\hline SR3 & Assisting agencies in IT strategy development and providing infrastructure & I2 & GR2, GR7 \\
\hline SR4 & Promoting the need for strategic IT planning among agency management & I6 & \\
\hline SR5 & Including ITSM as an imperative practice in government & I6, I7 & \\
\hline SR6 & $\begin{array}{l}\text { Seeking the opportunities for streamlining the technology environment, for } \\
\text { adopting standards and for improving the use of IT budgets }\end{array}$ & I8 & GR5 \\
\hline SR7 & Integrating existing IT initiatives across agencies & I10 & GR5, GR9 \\
\hline
\end{tabular}

\subsection{Usage of WG-ITSM Toolset}

This section describes how the requirements in Table 6 were partly supported by the toolset presented in Section 5.2. The WG-ITSM toolset was implemented in three pilot agencies, involving stakeholder workshops with agency management to develop IT visions and goals, and strategy sessions with unit heads to develop IT strategies. The guidelines and templates [6][7] were used to guide the sessions. With unit strategies available, agency-level IT strategies were consolidated and refined into IT objectives, with specific measures for evaluation, and initiatives to fulfill IT objectives were identified and developed into projects. The produced strategies were uploaded into the Strategy Management System [23] and a training program in using the WG-ITSM framework was delivered. However, a number of WG-ITSM requirements, particularly SR1, SR4 and SR5, are yet to be implemented. 


\section{Validation}

Based on the case study presented in Section 6, this section presents some arguments in favor of the validity of the WG model and generic WG-ITSM requirements, and establishes the coverage of the WG-ITSM toolset by mapping specific requirements to the toolset elements responsible for addressing them.

Validating the WG model - The validation of the WG model entails confirming the elements and relationships between them based on empirical results. From the analysis in Section 6.3, leadership and coordination stand out as perceived determinants for the WG approach. The findings also confirm legislation as a key factor for implementing the WG approach. The findings on the barriers to obtaining concrete WG benefits in Section 6.2 (F4) cover the list of barriers shown in Figure 3. In addition to validating our model, these results are significant in at least two ways. First, they reinforce the importance of leadership in WG initiatives as indicated in [9][11]. Second, they reconfirm the importance of coordination as well as raise the prominence of legislative factors in WG initiatives.

Validating the WG-ITSM generic requirements - The validation is carried out by determining the extent to which the specific WG-ITSM requirements from the case study (Table 6) are covered by the generic requirements (Table 4). Table 7 shows that the generic requirements cover most of the specific requirements except SR4 and SR5.

Table 7: Generic versus Specific WG-ITSM Requirements

\begin{tabular}{r|l} 
Generic Requirements & Specific Requirements \\
\hline GR1 & SR1 \\
\hline GR2 & SR3 \\
\hline GR3 & \\
\hline GR4 & SR1, SR2 \\
\hline GR5 & SR6 \\
\hline GR6 & \\
\hline GR7 & \\
\hline GR8 & SR3, SR6 \\
\hline GR9 & SR7
\end{tabular}

Coverage of the WG-ITSM Toolset - The adequacy of the WG-ITSM toolset is justified in Table 8. For each specific requirement in Table 6, the table explains which toolset element, if any, supports this requirement and how. The table shows that all requirements are directly supported by the toolset except SR4 and SR5.

Table 8: WG Specific Requirements versus WG-ITSM Toolset Elements

\begin{tabular}{l|l|l}
\hline Requirement & Element & How the Element Supports the Requirement \\
\hline SR1 & MM, SMS & $\begin{array}{l}\text { MM helps identify dependencies between strategies from different perspectives, } \\
\text { while SMS supports this feature and reports on it through its strategy map. }\end{array}$ \\
\hline SR2 & SG, ST & $\begin{array}{l}\text { The guidelines SG and templates ST provide detailed guidelines, descriptive } \\
\text { models and instruments to support agencies in developing IT strategies. }\end{array}$ \\
\hline SR3 & $\begin{array}{l}\text { smXML, } \\
\text { SMS }\end{array}$ & $\begin{array}{l}\text { smXML and SMS provide tools to help agencies develop and manage their IT } \\
\text { strategies. Mentoring could be addressed by a capacity-building program. }\end{array}$ \\
\hline SR4 & $\begin{array}{l}\text { This requirement cannot be directly satisfied by the toolset. Advocacy and } \\
\text { capacity building programs are required to achieve this. }\end{array}$ \\
\hline SR5 & $\begin{array}{l}\text { This requirement cannot be directly addressed by the framework since it requires } \\
\text { administrative and regulatory interventions. }\end{array}$ \\
\hline SR6 & $\begin{array}{l}\text { SMS maintains a WG IT strategy database with analytic and reporting features to } \\
\text { determine the alignment and common strategy elements across agencies. }\end{array}$ \\
\hline SR7 & $\begin{array}{l}\text { SMXML includes analytical features to support the identification of related } \\
\text { SMS }\end{array}$ & $\begin{array}{l}\text { SMitiatives, represented in smXML. } \\
\text { in }\end{array}$ \\
\hline
\end{tabular}




\section{Discussion}

The results from the case study confirm the complexity of developing and instituting WG initiatives in general and WG-ITSM in particular. While the adoption of frameworks with sound theoretical and practical foundations tends to improve the chances of success, such frameworks are hardly available. Foundational insights into the WG approach are only emerging through the case studies from United Kingdom, Australia, United States, Canada, New Zealand and Norway. Guided by relatively mature understanding of collaboration in government, this article reports an effort to synthesize the features of various WG practices into a WG model and to validate this model in practice.

Going by the case study, even with a guiding WG model and knowledge of concrete WG-ITSM requirements, expected results may be difficult to achieve. For instance, both the WG model and the case study findings show that communicating the shared objectives across government and facilitating interactions among agencies to seek the achievement of individual and collective goals is essential for agency participation. More generally, maintaining trust, reciprocity and other WG concerns (Table 2) is critical. In addition, how the four roles described in [13] are played will determine how well the WG requirements can be addressed. For instance, the case study shows the need for the constitution-building and contributor roles to support advocacy and capacity building efforts respectively.

From a pragmatic perspective, an initial strategy for WG-ITSM could be to drive the acceptance of the WG-ITSM framework by agencies towards de-facto standardization. For example, encouraging agencies to document their IT strategies using a centralized strategy management system creates opportunities for strategy integration across agencies. This is similar to [29] where local municipalities are encouraged to use the same applications. However, technology-related acceptance frameworks such as UTAUT [15] identify performance expectancy, effort expectancy and social influence as major determinants, with intention and facilitating conditions as the prime usage factors [15]. Considering the EGOV diffusion model [21], meaningful uptake of any technology in government will depend on how easy the agencies find the tools and the perception of the impact of such tools on agency performance. This makes capacity building to introduce WG-ITSM necessary but insufficient, given the passive nature of this type of participation, for adopting a WG approach.

While this paper contributed to better understanding of the WG initiatives, we are still far from developing a theory of WG. However, the WG model provides an initial framework for in-depth investigation, both quantitative and qualitative, of the relationships between leadership, structure and coordination on the one hand, and the development and sustainability of the WG capability on the other. We are also interested in harnessing the dynamic capabilities associated with the five stages of joined-up government [9] in operationalizing the WG model.

\section{Conclusions}

This research aimed at contributing to better understanding of the Whole-of-Government (WG) approach and applying this understanding to IT Strategy Management (ITSM). Our approach has been to learn from the WG cases, to synthesize common features and ground them on well-established collaboration theories, and to apply the resulting WG-ITSM model in government. Specifically, this article makes three contributions: 1) it articulates the WG model and partially demonstrates its validity, 2) it validates the generic WG-ITSM requirements derived from the WG model using the data obtained from a case study, and 3) it provides a set of models, guidelines and tools to support the implementation of the WG-ITSM requirements.

The WG model prescribes broad activity areas including leadership, coordination, governance and administration, and provides core principles to guide policy makers in implementing these activities. The set of barriers produced from the case study provides additional evidence to justify the need for policy makers to explicitly address these issues when developing WG initiatives. Thus our conclusion is that WG-ITSM is a complex undertaking that, guided by proper risk assessment, requires a well articulated strategy for developing the required capabilities.

While the WG model and WG-ITSM framework provide a good starting point for further research and support for the WG-ITSM practice, more empirical studies based on real-life cases are needed to effectively guide the development and sustainability of the WG practice in the IT area. 


\section{Acknowledgements}

This work was partly supported by Macao Foundation, Macao SAR Government, through the e-Macao Program.

\section{References}

[1] A. C. Hax and N.S. Majluf, Strategy and the Strategy Formation Process, 1986.

[2] A. Lawson-Body, L. Mukankusi, and G. Miller, An Adaptation of the Balanced Scorecard for E-Government Service Delivery: A Content Analysis, Journal of Service Science, vol. 1, 2008, pp. 75-82.

[3] A. M. Cresswell, G.B. Burke, and T.A. Pardo, Advancing Return on Investment Analysis for Government IT: A Public Value Framework, 2006.

[4] A. M. Thomson and J.L. Perry, Collaboration Processes: Inside the Black Box, Public Administration Review, 2006.

[5] A. Moseley, Joined-Up Government: Rational Administration or Bureaucratic Politics?, Public Administration Committee Annual Conference, University of Glamorgan, 2009, pp. 1-26.

[6] A. Ojo, B.P. Shah, and T. Janowski, Strategic IT Planning for Public Organizations - Toolkit, eMacao Systems Report, No. 077, April 2008, at: http://www.emacao.egov.iist.unu.edu/index.php/emacao/projects/Strategic-IT-Planning-for-Public-Agencies

[7] A. Ojo, B.P. Shah, and T. Janowski, Strategic IT Planning for Public Organizations - Templates, eMacao Systems Report, No. 078, April 2008, at: http://www.emacao.egov.iist.unu.edu/index.php/emacao/projects/Strategic-IT-Planning-for-Public-Agencies

[8] Australian Public Service Commission, Connecting Government: Whole-of-Government Responses to Australia's Priority Challenges, 2004.

[9] B. Klievink and M. Janssen, Realizing Joined-Up Government — Dynamic Capabilities and Stage Models for Transformation, Government Information Quarterly, vol. 26, Apr. 2009, pp. 275-284.

[10] C. D. Coning, H. Lurås, N.N. Schia, and S. Ulriksen, Norway's Whole-of-Government Approach and its Engagement with Afghanistan, 2009.

[11] C. Huxham, Leadership in the Shaping and Implementation of Collaboration Agendas: How Things Happen in a (Not Quite) Joined-up World, Management, vol. 43, 2000, pp. 1159-1175.

[12] D. Sedera, G. Gable, and M. Rosemann, A Balanced Scorecard Approach to Enterprise Systems Performance Measurement, 12th Australasian Conference on Information Systems, 2000.

[13] E. Bardach, Can Network Theory Illuminate Interagency Collaboration?, Workshop on Network Analysis and Innovations in Public Programs, Sept. 29- Oct. 1, 1994, LaFollette Institute of Public Affairs, University of Wisconsin-Madison, 1994, pp. 1-24.

[14] E. Estevez, A. Ojo, and T. Janowski, Idioms for Collaborative Government Networks - Conceptualization and Applications to Seamless Services, 11th IFIP Working Conference on Virtual Enterprises, Saint-Etienne, France, 11-13 October 2010, Springer, 2010, pp. 219-226.

[15] E. Korteland and V. Bekkers, Diffusion of E-government Innovations in the Dutch Public Sector: The Case of Digital Community Policing, Electronic Government, Springer, 2007, p. 252-264.

[16] H. Mintzberg, The Rise and Fall of Strategic Planning, Pearson Education, 2000.

[17] I. Cobbold and G. Lawrie, The Development of the Balanced Scorecard as a Strategic Management Tool, PMA Conference, 2002.

[18] IT Governance Institute, Enterprise Value: Governance of IT Investments - The Val IT Framework 2.0, 2008.

[19] J. Baker, Quick Impact Projects: Towards a 'Whole of Government' Approach, A Graduate Journal of International Affairs, vol. 8, 2007, pp. 1-21.

[20] J. Fedorowicz, U. Gelinasjr, J. Gogan, and C. Williams, Strategic Alignment of Participant Motivations in eGovernment Collaborations: The Internet Payment Platform Pilot, Government Information Quarterly, vol. 26, Jan. 2009, pp. 51-59.

[21] J. M. Bryson, A Strategic Planning Process for Public and Non-profit Organizations: A Guide to Strengthening and Sustaining Organizational Achievement, Jossey-Bass, 2004.

[22] J. Ramon Gil-Garcia, I. Chengalur-Smith, and P. Duchessi, Collaborative e-Government: Impediments and Benefits of Information-Sharing Projects in the Public Sector, European Journal of Information Systems, vol. 16, Apr. 2007, pp. 121-133.

[23] K. Nguyen, A. Ojo, and T. Janowski, Strategic IT Planning for Public Organizations - System, eMacao Systems Report, No. 079, April 2008, available at: 
http://www.emacao.egov.iist.unu.edu/index.php/emacao/projects/Strategic-IT-Planning-for-Public-Agencies

[24] K. Parisopoulos, E. Tambouris, and K. Tarabanis, Transformational Government in Europe: A Survey of National Policies, M.D. Lytras et al (Eds), WSKS 2009, LNAI 5736, Springer-Verlag, 2009, pp. 462-471.

[25] L. Camarinha-Matos and H. Afsarmanesh, Towards a Reference Models for Collaborative Networked Organizations, Information Technology for Balanced Manufacturing Systems, BASYS2006, Niagra Falls, Canada, 4-5 September 2006, Springer, 2006, pp. 1-10.

[26] L. F. Luna-Reyes and D.L. Andersen, Collecting and Analyzing Qualitative Data for System Dynamics: Methods and Models, System Dynamics Review, vol. 19, 2003, p. 271-296.

[27] L. J. Black, A.M. Cresswell, T.A. Pardo, F. Thompson, D.S. Canestraro, M. Cook, L.F. Luna, I.J. Martinez, D.F. Andersen, and G.P. Richardson, A Dynamic Theory of Collaboration: A Structural Approach to Facilitating Intergovernmental Use of Information Technology, 36th Hawaii International Conference on System Sciences (HICSS’03), IEEE Computer Society, 2003.

[28] M. Isoraite, The Balanced Scorecard Method: From Theory to Practice, Intellectual Economics, vol. 1, 2008, pp. 18-28.

[29] M. Sorrentino and E. Ferro, Does the Answer to eGovernment Lie in Intermunicipal Collaboration? An Exploratory Italian Case Study, EGOV 2008, W.M. A., H.J. Scholl, and E. Ferro (Eds.), LNCS 5184, SpringerVerlag Berlin Heidelberg, 2008, pp. 1 - 12.

[30] M.K. Sein, Conceptualizing the ICT Artifact: Toward Understanding the Role of ICT in National Development, Information Society, vol. 20, 2004, pp. 15-24.

[31] OECD, Whole of Government Approaches to Fragile States, Paris, France, 2006.

[32] P. Gershon, Review of the Australian Government's Use of Information and Communication Technology, 2008.

[33] P. R. Niven, Balanced Scorecard Step-by-Step for Government and Nonprofit Agencies, Wiley, 2008.

[34] R. Nag, D.C. Hambrick, and M.J. Chen, What is Strategic Management, Really? Inductive Derivation of a Consensus Definition of the Field, Strategic Management Journal, vol. 28, 2007, p. 935-955.

[35] R. S. Kaplan and D.P. Norton, Using the Balanced Scorecard as a Strategic Management System, Harvard Business Review.

[36] S. Hunt, Whole-of-Government: Does Working Together Work?, 2005.

[37] S. Jenner, Realising Benefits from Government ICT Investment - a Fool's Errand?, Academic Publishing International Ltd, 2009.

[38] S. S. Dawes and L. Préfontaine, Understanding New Models of Collaboration for Delivering Government Services, Communications of the ACM, vol. 46, 2003, p. 40-42.

[39] S.S. Dawes, Interagency Information Sharing: Expected Benefits, Manageable Risks, Journal of Policy Analysis and Management, vol. 15, no. 3, 1996, pp. 377- 394.

[40] Strategy Markup Language Community of Practice, Strategy Markup Language (StratML), at: http://www.xml.gov/stratml/index.htm

[41] Strategy Markup Language Community of Practice, Strategy Markup Language Value Proposition, 2006, at: http://www.xml.gov/stratml/index.htm

[42] T. Christensen and P. Lægreid, The Whole-of-Government Approach to Public Sector Reform, Public Administration Review, vol. 67, 2007, pp. 1059-1066.

[43] T. Hoel and P. Hollins, Learning Technology Standards Adoption - How to Improve Process and Product Legitimacy, 8th IEEE International Conference on Advanced Learning Technologies, ICALT'08, IEEE, 2008, pp. 587-589.

[44] T. H. Stanton, Improving Collaboration by Federal Agencies: An Essential Priority for the Next Administration, 2008.

[45] T. P. Morgan, Global IT Spending Will Rise in 2009 (slightly), 2009.

[46] United States General Accounting Office (GAO), Results-Oriented Government - Practices That Can Help Enhance and Sustain Collaboration among Federal Agencies, 2005.

[47] United States General Accounting Office (GAO), Measuring Performance and Demonstrating Results of Information Technology Investments: Executive Guide, 1998. 